\title{
Autonomia do educando na escola fundamental: um tema negligenciado ${ }^{1}$
}

\section{Student's autonomy in the elementary school: a neglected issue}

\author{
Vitor Henrique Paro ${ }^{2}$
}

\begin{abstract}
RESUMO
Este artigo trata da autonomia (no processo pedagógico e na prática escolar cotidiana) como direito do educando e como requisito imprescindível para a educação de qualidade. É parte de estudo mais amplo sobre a estrutura da escola e se baseia em pesquisa qualitativa realizada em escola estadual localizada na cidade de São Paulo. Aos aportes teóricos provenientes das ciências da educação, o ensaio agrega a análise de dados de entrevistas com educadores e de observações das práticas cotidianas e das atividades pedagógicas desenvolvidas na escola. Da autonomia do educando são ressaltadas as implicações tanto políticas quanto didáticas, para concluir em favor da importância do tema e alertar sobre sua paradoxal negligência pelas políticas públicas educacionais.
\end{abstract}

Palavras-chave: autonomia do educando; ensino fundamental; direito à educação.

\begin{abstract}
This article deals with the autonomy (in the pedagogical process and in daily school practice) as a student's right and an indispensable requirement for high quality education. It is part of a broad study about the structure of the school and it is based on a qualitative research done at a public school in São Paulo city. To the theoretical contribution from the educational science, this essay adds an analysis of data about interviews with educators and
\end{abstract}

${ }^{1}$ Este trabalho é resultado de pesquisa que teve financiamento parcial do Conselho Nacional de Desenvolvimento Científico e Tecnológico (CNPq).

${ }^{2}$ Professor Titular da Faculdade de Educação da Universidade de São Paulo, Brasil. E-mail: vhparo@usp.br. 
observations of daily pedagogical practice and activities carried out at school. The implications of both political and educational autonomy of the student are emphasized, in order to conclude in favor of the importance of this issue and warn about its paradoxical neglect by the public educational policies.

Keywords: student's autonomy; elementary school; right to education.

\section{Introdução}

Pesquisa de cunho qualitativo que realizei no sistema estadual paulista de ensino, de março de 2007 a fevereiro de 2010, teve por objetivo geral estudar a estrutura da escola fundamental à luz de um conceito de educação como prática democrática. O trabalho de campo, realizado durante o ano letivo de 2008, deu-se em escola localizada na capital do estado com oferta de ensino fundamental da primeira à quarta série. A adoção de um conceito amplo de "estrutura total da escola" (CÂNDIDO, 1974, p. 107) resultou no envolvimento de uma multiplicidade de temas que são tratados no relatório final da pesquisa (PARO, 2010). Neste artigo procuro abordar um desses temas, o da autonomia do educando, que, por mais que tenha frequentado sempre as elaborações teóricas, as práticas e as recomendações dos mais importantes educadores e estudiosos da educação no correr da história, ainda não tem sido contemplado com a importância que merece nas políticas públicas voltadas para a escola fundamental.

O tema da autonomia do aluno no contexto escolar, começando pela situação de ensino e se expandindo para as tomadas de decisões no âmbito da administração da escola, é de tão ampla extensão que quase se pode dizer que coincide com o tema da própria educação escolar. Não pode haver verdadeira educação, se não se consegue a autonomia do educando, ou melhor, se ele não $s e f a z$ autônomo, isto é, alguém que se governa por si mesmo. O presente artigo não tem a pretensão de esgotar a questão, mas apenas tocar em aspectos relevantes da matéria, suscitados pelo trabalho de campo, de modo a contribuir para a reflexão sobre o tema no campo das políticas públicas de educação.

\section{A questão da autonomia}

Certamente, uma das questões mais espinhosas com que se defronta quando se trata de conceber uma educação escolar verdadeiramente democrática diz res- 
peito à autonomia que deve caber aos educandos na escola. No ensino tradicional, em que o aluno é tido como mero receptor de conhecimentos e informações, o assunto é facilmente resolvido com a aceitação de que às crianças cabe apenas obedecer aquilo que é estabelecido pelos adultos, estruturando-se a escola de modo a atender esse mandamento. Por isso, a organização para a obediência prevalece não apenas nas atividades-meio, mas também nas atividades-fim. Quando, porém, se toma como pressuposto a liberdade dos educandos para se fazerem sujeitos do ensino, o processo se torna bastante complexo, porque não se trata tão somente de dar ou negar autonomia. Autonomia, a exemplo do que acontece com a educação, é algo que deve ser desenvolvido com a autoria do próprio sujeito que se faz autônomo. Isso acarreta implicações imediatas para a forma mesmo de realizar-se o processo ensino-aprendizagem.

$\mathrm{Na}$ escola tradicional está muito bem assentado que a situação de ensino se dê na forma de um professor comunicando-se, numa sala de aula, com uma turma de alunos sentados em suas carteiras enfileiradas, durante praticamente todo o período de aula. Mas, num contexto educativo em que se supõe a participação ativa dos educandos, considerando seus interesses e necessidades, como serão administrados o tempo e o espaço, tendo em vista o melhor desenvolvimento do aprendizado? Como serão organizadas as turmas ou grupos de estudantes? Como serão dispostos os espaços e equipamentos? Que tamanho e que arranjos espaciais terão as salas de aulas e demais ambientes de aprendizado e convivência? Essas e outras perguntas relacionadas à maneira de se processar as atividades-fim da escola precisam ser respondidas quando se sente a necessidade de romper com a monótona sala de aula tradicional, na qual os estudantes vão, não para participar como sujeitos, mas apenas para receber informações.

Todavia, a situação de ensino não é o único momento que deve ser objeto de preocupação quando se toca no tema da autonomia dos alunos. É preciso considerar também a questão da participação discente nas tomadas de decisão da escola de um modo geral. E aqui não se trata de considerar apenas os mecanismos institucionais de participação (grêmio estudantil, assembleia de estudantes etc.), mas principalmente a controversa discussão a respeito do sentido e da medida dessa participação. Quanto ao sentido ou à legitimidade da participação, parece não haver dúvida, de uma perspectiva de educação democrática, de que, à necessária condição de sujeito do educando prevalecente nas atividades-fim, deve corresponder um poder de decisão discente no funcionamento geral da instituição educativa. Na verdade, não faz sentido uma descontinuidade entre esses dois momentos, e, em todas as experiências bem sucedidas de educação democrática (cf. BREMER; VON MOSCHZISKER, 1975; PISTRAK, 1981; FREINET, 1996; CANÁRIO et al., 2004; MAKARENKO, 2005; NEIL, 1976; 
ESCOLA DE BARBIANA, [20-?]), sempre teve destaque a participação dos estudantes na organização e funcionamento da instituição educativa.

No entanto, quando se trata da medida da participação, é preciso um cuidado maior para não se cair nem na restrição desmedida, sob o pretexto de que as crianças não sabem o que querem, nem no mero espontaneísmo, sob a alegação de que não se deve inibir nenhum desejo das crianças. No primeiro caso se nega a subjetividade do educando, no segundo se o abandona à própria sorte. O que se precisa ponderar é que, se, por um lado, a autonomia não pode ser outorgada, mas se desenvolve com a participação do próprio educando, por outro lado, ela não nasce do nada, mas exige a mediação do educador. Essa ponderação está bem presente nas palavras de Pistrak (1981), para quem

é preciso dizer francamente que, sem o auxílio dos adultos, as crianças podem, talvez, se organizarem sozinhas, mas são incapazes de formular e de desenvolver seus interesses sociais, isto é, são incapazes de desenvolver amplamente o que está na própria base da auto-organização. Acrescentaríamos que o pedagogo não deve ser estranho à vida das crianças, não se limitando a observá-la. Se fosse assim, de que adiantaria nossa presença na escola? Exclusivamente ao ensino? Mas, de outro lado, o pedagogo não deve se intrometer na vida das crianças, dirigindo-a completamente, esmagando-as com sua autoridade e poder. (PISTRAK, 1981, p. 140)

O mesmo educador reconhece a necessidade de buscar a medida adequada da interferência do adulto, acrescentando:

É preciso encontrar a linha de comportamento justa, evitando, sem dúvida, o esmagamento da iniciativa das crianças, a imposição de dificuldades a sua organização, mas permanecendo, de outro lado, o companheiro mais velho que sabe ajudar imperceptivelmente, nos casos difíceis, e, ao mesmo tempo, orientar as tendências das crianças na boa direção. Para falar de forma mais concreta, isto quer dizer que é preciso suscitar nas crianças preocupações carregadas de sentido social: ampliá-las, desenvolvê-las, possibilitando às próprias crianças a procura de formas de realização. (PISTRAK, 1981, p. 140)

Para qualquer política pública comprometida com a democratização da escola fundamental, a consideração dessas questões deve reforçar a convicção de 
que elas merecem uma reflexão profunda de modo a subsidiarem a proposição de medidas e a criação de mecanismos institucionais que garantam e estimulem a participação autônoma das crianças nos assuntos que dizem respeito a sua educação escolar.

\section{A autonomia na prática}

Conforme mencionei, a escola estadual em que foi realizado o trabalho de campo só abriga a primeira parte do ensino fundamental, também chamada de Ciclo I, que inclui alunos de primeira a quarta série. Não há grêmio estudantil ou qualquer outra instituição que represente os interesses discentes. Por outro lado, as crianças não têm idade mínima necessária para participar do conselho de escola. As considerações aqui feitas se fundamentam nas observações de campo (aulas, reuniões, corredores, pátios, atendimentos discentes etc.) e nas entrevistas realizadas com professores e demais trabalhadores da escola.

Um tema que sempre se apresenta quando se fala de autonomia de crianças em idade escolar, especialmente quando se refere ao ensino fundamental, é a questão da disciplina ou comportamento dos alunos. Esse tema apareceu reiteradamente nas entrevistas na Escola Estadual (E. E.) Célia Cintra ${ }^{3}$, mas sem constituir propriamente um problema dessa escola. Em geral, ao se tocar na questão da autonomia estudantil, os entrevistados se reportavam aos problemas disciplinares, com a ressalva de que na Escola Célia Cintra é muito difícil encontrá-los. O que as pessoas alegam é que isso se dá devido à escola atender crianças menores, da primeira metade do ensino fundamental, muito menos "indisciplinadas" e "violentas" do que as do chamado Ciclo II.

Inês, secretária da escola, diz que não é muito frequente o professor da Célia Cintra enviar aluno para a diretoria. Não tem visto muito problema de disciplina também. Antônia, auxiliar de professora ${ }^{4}$, diz:

\footnotetext{
${ }^{3}$ Para manter o sigilo das fontes, os nomes da escola pesquisada e das pessoas entrevistadas são fictícios.

${ }^{4} \mathrm{O}$ auxiliar de professor trata-se, em síntese, do famigerado "segundo professor em sala de aula", propalado pelo Governo Estadual, mas que nada mais é do que um estudante de graduação que recebe uma pequena bolsa de estudos para ele "ajudar" o professor de primeiro ou segundo ano do ensino fundamental.
} 
A disciplina, você não pode ser severo com o aluno. Está certo. Mas também você não pode deixar o aluno fazer o que ele quer. Então, eu acho que a disciplina você vai ter que dividir com o aluno. Você vai ter que negociar com o aluno, conversar com ele e falar para ele: 'Olha, eu estou aqui para ajudar vocês, mas vocês estão aqui para me ajudar.'

O raciocínio de Antônia parece ter a lógica do adulto em geral, que não percebe que, com a criança, não basta combinar, porque ela não segue a mesma lógica. É preciso oferecer condições que a leve a respeitar o que se combina. É preciso também ter muito cuidado com aquilo que se combina. É preciso saber se a criança terá condições (em vista de seu desenvolvimento biopsíquico) de cumprir o combinado.

Nas observações feitas na escola não foram percebidos atos de indisciplina ou violência por parte dos alunos. Nas entrevistas, um ou outro aluno é referido pela professora como mais indisciplinado. Elaine, professora da primeira série, afirma que sua classe é muito boa em termos de disciplina, que os alunos aprendem muito bem. Para ela, o aluno deve ter a liberdade de levantar do lugar, de pedir um material emprestado, de conversar com o outro, mas muito professor entende isso como indisciplina, quando, na verdade, é uma necessidade da própria criança, pela idade em que ela está. Conta que em sua classe só há uma aluna que é problemática: "A sala era uma sala assim que eles eram bem tranquilos. A sala ficou um pouco desestabilizada na questão disciplina por conta de uma aluna, que está aqui que, nossa! ela deixa às vezes a sala de pernas pro ar."

Tive ocasião de presenciar um dos episódios com essa aluna. Estando sentado num banco do pátio de entrada da escola, à espera da professora Vanessa para entrevistá-la, ouvi alguns gritos (que depois fui saber que eram da professora Elaine) vindos de uma das salas: "Chega! Assim não dá!” etc. Permaneci no pátio, enquanto aguardava para falar com a Vanessa. Apareceu uma garotinha dizendo que a professora a pôs para fora da sala. Estava um pouco encabulada, sentou-se a meu lado, e logo em seguida passou Vera Sanches, a coordenadora pedagógica. A aluna diz também para ela que a professora a pôs para fora. Vera Sanches pergunta por que e, com muito carinho, a leva de volta para sua sala. Não acompanhei o que aconteceu em seguida, mas na entrevista com Elaine esta me reportou o acontecido, dizendo que há ocasiões em que é impossível manter a calma.

Marilda, professora da quarta série, constitui uma exceção ao se referir ao comportamento dos alunos na E. E. Célia Cintra. Diz que um problema que tem na escola é a disciplina. 
Eles não têm respeito, entendeu? Eles não sabem se colocar no lugar deles. Eu sou muito brincalhona, eu deixo elas falarem o que pensam, eu gosto de ouvir o que eles têm a dizer... Mas, assim, eu acho que tem hora para tudo: hora para bater papo, hora para se discutir um assunto que está em discussão ali, mas eles brincam muito, eles estão acostumados a dar muita festa dentro da sala de aula.

Mas ela diz também que isso não se torna problema com relação a seus alunos e afirma que a solução para a indisciplina é saber manter a autoridade, respeitando a criança, aproximando-se dela. "Não é difícil você participar de uma criança e ela ter respeito por você. Não é difícil."

No exame do conceito de disciplina, não convém deixar de considerar a contribuição de Johann Friedrich Herbart, um dos clássicos da Pedagogia, ao estabelecer a diferença entre governo e disciplina. $\mathrm{O}$ governo diria respeito às ordens que a criança deve cumprir inapelavelmente, independentemente de sua vontade e compreensão; enquanto que a disciplina seria de caráter mais "flexível" tratando de normas que se transmitem à criança, como formação, no contexto de sua aprendizagem.

Por isso, dirá Herbart: "O governo, nos casos em que recorre à pressão, pretende que seja simultaneamente sentido como poder." (2003, p. 184, grifo no original) A autoridade embutida na proibição do manuseio de uma arma por parte de uma criança de três anos, por exemplo, não pode depender de sua vontade, nem se pode esperar que a criança compreenda as razões por que está sendo proibida. Nesses casos, continua Herbart, "a pressão tem de se empregar sem concessões, a não ser a imposição da intenção; deve-se ser frio, breve e seco, dando a entender ter tudo esquecido, logo que a questão tenha passado" (p. 184). Mas não é assim quando se trata da disciplina:

É já muito diferente o acento da disciplina. Não deve ser breve e agudo, mas prolongado, persistente, de penetração lenta, só devendo gradualmente deixar de atuar! Pois que a disciplina deve ser entendida como formativa. Certamente que não no sentido de esta impressão constituir precisamente o essencial da sua força formativa, mas não pode esconder a intenção de formar. E ainda que o pudesse: para ser simplesmente suportável tem de a apresentar. Quem se não oporia a um tratamento com que, por vezes, sofre a alegria e de que resulta um sentimento constante de dependência ou, pelo menos, quem se não fecharia interiormente, se nela se não pressentisse qualquer princípio de ajuda e de elevação? - A disciplina não deve tocar erradamente a alma, 
nem tão pouco ser sentida como contrária à sua finalidade. $\mathrm{O}$ educando não se lhe deve opor interiormente de modo nenhum, nem mover-se em diagonal como que impelido por duas forças. Mas donde receber uma receptividade aberta e límpida, se não da crença da criança na força e intenção benéfica do educador? E como poderia um comportamento frio, estranho e de repulsa, conduzir a essa crença? [...] (HERBART, p. 185-186, grifos no original).

Em suma, pode-se dizer que governo se impõe, disciplina se ensina. Todavia, essa imposição implícita nas regras "intocáveis" e "inflexíveis" do governo não é de modo nenhum incompatível com a autonomia do educando, visto que essas normas também são históricas (ou seja, criadas pelos homens na produção social de sua existência) e, nesse sentido, nada arbitrárias. É inerente a toda sociedade, em especial a sociedades democráticas, o estabelecimento de regras de convivência, de tal modo que algumas sejam consideradas "pétreas", especialmente aquelas destinadas à promoção e preservação da integridade física e social. Não quer dizer que essas regras nunca sejam mudadas, mas que, por sua natureza e objetivos gozam de maior permanência. Numa democracia, essas regras são criadas pela ação e vontade de cidadãos, no exercício de sua autonomia. Daí a importância da disciplina e de seu caráter formativo, na medida em que, por meio da relação pedagógica, se consegue formar cidadãos, ou seja, os que participam como autores na elaboração das regras que são objeto do governo e da disciplina.

Desse ponto de vista, na medida em que se concretiza no contexto de uma relação pedagógica, supondo, portanto, a condição de sujeito, ou seja, o envolvimento da vontade do educando, a disciplina só se realiza e se legitima como autodisciplina. Recorrendo novamente a Herbart (2003), pode-se afirmar que "a disciplina não tem o seu verdadeiro impacto senão depois que teve oportunidade de realçar ao educando parte do seu eu mediante uma aprovação profunda (não propriamente elogio!)." (p. 188, grifos no original)

Para o bom ensino, portanto, a disciplina é apenas mais um elemento cultural do qual os alunos devem se apropriar pela educação. Vera Sanches, a coordenadora pedagógica, diz que, em termos de disciplina dos alunos, na Célia Cintra os problemas são apenas pontuais. O recreio é dividido (em virtude da pequenez do espaço): primeiras e segundas séries num momento e terceiras e quartas no outro. Registram-se pouquíssimos casos de briga e de agressão entre alunos. Vanessa, professora da segunda série, diz que não tem problemas com disciplina dos alunos. Isso foi comprovado na observação de sua aula, em que percebi uma classe notavelmente bem comportada, e orientada de modo 
tranquilo pela professora que conseguia a colaboração das crianças com sua atenção e dedicação ao estudo.

Márcia, a vice-diretora, acha que a disciplina no Ciclo I (primeira a quarta séries) é bastante tranquila, o que não acontece no Ciclo II (quinta a oitava séries) e no ensino médio. Perguntada se não é normal que a criança queira correr e brincar, Márcia diz que isso tem limite. Diz que geralmente a criança corre na escola porque as mães não deixam correr em casa. Diz que a escola tem muito aluno de classe média, mas que há muito aluno "carente" também, que não tem o apoio em casa. "E, por incrível que pareça, quanto mais carente, mais indisciplinado ele é. Não sei porquê."

Não deixa de ser insólita a reclamação, de certa forma generalizada na escola pública brasileira, com relação à condição de carência e falta de cultura do grande contingente de alunos que recebe. Ninguém aceitaria de um médico, por exemplo, a reclamação de que só lhe mandam pessoas doentes para seu consultório. É ponto pacífico que os que padecem de algum mal físico, os carentes de saúde, são precisamente o objeto da ação profissional do médico. Por que, então, não se espantar diante da alegação do professor ou dos responsáveis por políticas educacionais de que uma das causas por que o ensino não vai bem é o fato de que as crianças são "carentes"? Seria algo até muito engraçado, se não fosse dramática a situação das crianças das camadas populares, que são ainda mais discriminadas precisamente porque têm menos cultura, ou seja, aquilo que se supõe dever da escola lhes oferecer.

A escola, que já é algo inerentemente estranho em relação ao ambiente familiar mesmo para as crianças das camadas privilegiadas, torna-se ainda mais difícil para a integração das crianças provindas de lares das camadas populares. Para estas, se torna ainda mais real aquele ambiente de medo a que se refere Gilmar Rocha (2008), em trabalho que examina a relação entre a violência na escola e a síndrome do medo contemporâneo:

[...] É curioso observar o quanto o medo e a violência parecem inerentes à instituição Escola. Como bem lembra Tuan ${ }^{5}$ o ambiente da escola representa uma primeira experiência de medo para as crianças que ingressam na instituição. Para começar, as crianças têm que aprender a lidar com um mundo novo: desde o ambiente barulhento, às relações com outras crianças e adultos estranhos, com os jogos de competitividade, com o ridículo das performances corporais, com o escárnio, o riso e o deboche dos mais velhos, etc. Assim, muitas são as formas de medo

\footnotetext{
${ }^{5}$ TUAN, Y.-F. Paisagens do medo. São Paulo: Unesp, 2005.
} 
na escola. Por exemplo, medo de prova, medo do professor, medo de não aprender, pois representam, ao menos em um primeiro momento, situações que fogem ao controle, representam o desconhecido. Mas, paradoxalmente, o custo de eliminar a violência e o medo, na maioria das vezes, tem sido pago com a violência e o medo. Ao menos é o que tem nos "ensinado" a história da escola moderna. E a percepção de medo aumenta, pois, agora, a escola parece desconhecer os alunos que tem. (ROCHA, 2008, p. 210; grifos meus.)

Também revela desconhecimento do ofício o educador que se espanta com a criança que corre, que grita, que pula e se expande. A educação, a autodisciplina, a autonomia do ser humano, deve dar-se a partir dessa sua natural expansividade quando criança, buscando fazê-lo crescer e tornar-se senhor de seus atos, sem coibir-lhe desnecessariamente sua espontânea expressão.

[...] A criança brinca e joga, e mais que o adulto, porque tem em si um potencial de vida que a faz procurar maior amplitude de reações: ela grita naturalmente em vez de falar, corre sem parar em vez de andar, depois adormece profundamente, com a colherada de sopa na boca, e nada a despertará até a manhã seguinte. A atividade que lhe é permitida ou tolerada pelos adultos e pelos elementos não basta para gastar todo esse potencial de vida, ela precisa de um derivativo que não pode imaginar totalmente, que se contenta em copiar da atividade dos adultos, adaptando-o à sua capacidade. (FREINET, 1998, p. 179-180)

Se o ensino público fundamental estivesse fundamentado em bases científicas que considerassem as necessidades específicas das crianças para viverem enquanto se educam, as escolas estariam muito mais servidas de espaços, de tempos e de atividades planejadas para as crianças darem vazão a sua vitalidade, especialmente para brincarem.

Brincar exige atividade física e/ou mental. O estímulo para brincar vem de dentro das crianças. É a maneira como elas aprendem a respeito do mundo. É inerentemente prazeroso e não requer nenhum objetivo. Quando um objetivo é mais importante do que a atividade, a atividade não é mais uma brincadeira. Em esportes competitivos, por exemplo, quando vencer torna-se mais importante do que o processo de jogar, os 
jogos ou partidas deixam de ser brincadeira. A habilidade de brincar e se divertir é um sinal de saúde [...]. (LINN, 2006, p. 95)

A escola, muitas vezes, diante da conduta "rebelde" do aluno - reveladora, mais que tudo, de uma vontade de expressar-se e de expandir toda sua energia vital -, abre mão de sua real função civil (GRAMSCI, 1978) e pedagógica, tratando o aluno com desconfiança, por meio de mecanismos de coerção e vigilância, em vez de utilizar toda a riqueza da relação educativa (fundada no diálogo e na confiança), de modo a ajudá-lo a crescer pessoalmente pela construção de uma personalidade sadia e rica de conteúdo cultural. Tal situação faz lembrar o repto dos rapazes da Escola de Barbiana ([20-?], p. 92), na carta que escrevem "a uma professora": "Além disso, de pé, a dois passos de mim, está a senhora. Quem sabe das coisas. Que é paga para me ajudar. / E ao contrário perde tempo me vigiando como se eu fosse um ladrão."

Mas sabemos que a promoção de uma competente relação pedagógica na escola exige um conhecimento técnico e uma visão crítica de mundo que falta, muitas vezes, ao professor. Por isso, a realidade das escolas, nas investigações que tenho realizado tem evidenciado que quase nunca a razão principal do fracasso em trabalhar democraticamente com os alunos é a maldade ou a má intenção do professor ou professora. Elaine, professora da primeira série, por exemplo, diz que gosta de fazer uma aula bastante descontraída, que rompe com os padrões tradicionais. Brinca com os alunos, canta, ouve música, faz rodas etc. Isso faz com que os alunos se sintam à vontade e ela recebe referências dos pais dizendo que os alunos gostam de ir à escola. Essa impressão de Elaine, todavia, não coincide muito com o que foi observado em sua aula. Embora, de fato, as 12 meninas e os 11 meninos de sua turma sejam bastante pacíficos, não fazendo muito barulho, nem desobedecendo a professora, sua aula é um tanto maçante, percebendo-se vários alunos que não fazem nada, parecendo bastante desinteressados. A bem da verdade, Elaine tenta lançar mão de alguns mecanismos que quebrem a formalidade da aula "tradicional", ora organizando os alunos em grupo, num grande círculo, ora procurando estimular sua atividade por meio da manipulação de objetos concretos, como recortar, pintar etc., mas tudo isso parece ser feito sem a adequada habilidade por parte da professora, não alcançando o fim desejado de tornar a aula mais prazerosa.

Sobre a participação de educandos nas decisões da escola, especialmente por representação nos órgãos de participação coletiva já existentes na escola fundamental (conselho escolar, conselho de classe, grêmio estudantil), os entrevistados da E. E. Célia Cintra, em geral, são favoráveis e criticam aqueles que procuram coibir essa participação. 
Raquel, diretora, diz: "O aluno não é escutado, o aluno muitas vezes não é respeitado - e aí eu vou generalizar mesmo - de primeiro [ano do ensino fundamental] até o terceiro ano do ensino médio.” À pergunta sobre o que significa isso, Raquel responde:

Que ninguém para um pouco para escutar os anseios. De quinta à oitava e o ensino médio, eu acho que seja por causa do conteúdo programático: o professor está tão preocupado com aquele conteúdo, que ele não tem a preocupação de parar e falar, porque é que o fulano tá pichando o teto da escola... o professor não escuta o aluno.

Raquel considera importante o grêmio estudantil, mas concorda que tem sido muito difícil de instituir nas escolas. "A única coisa que funciona é em época de eleição, que formam as chapas e aí fica aquela coisa bem movimentada." Sobre a participação do aluno no conselho de classe, diz que já fez isso em outra escola em que trabalhou.

Eu fiz, eu fiz no Silveira $\operatorname{Costa}^{6}$ e foi uma situação muito de saia justa, porque os professores ficaram muito incomodados; então, na segunda reunião que fizemos com os representantes, eles vieram com uma lista, que a coordenadora tinha dado para eles do que eles podiam falar. Ela já tinha dado um roteiro - sem o meu conhecimento [ênfase] - daquilo que eles poderiam falar. Porque, na primeira reunião, eles falaram tudo. A primeira reunião de conselho a gente faz um mapa da escola (é assim que eu encaro) daí a gente faz o diagnóstico de cada classe, daí a gente fala "a classe tal é assim"... Faz um mapeamento. E aí os alunos começaram a interagir, a falar... e eu até chamei mãe e pai, vieram acho que uns dois ou três.

Ainda sobre a participação dos alunos, Raquel afirma:

Primeiro lugar, a representatividade, aquela questão de ter um aluno em cada sala e ele ter a certeza que vai ser ouvido uma vez por semana, de

\footnotetext{
${ }^{6}$ Nome fictício. Refere-se à outra escola em que Raquel foi diretora.
} 
quinze em quinze dias, com reunião com a coordenação, ou com a reunião com um grupo de professores que estivessem ali para escutar os anseios.

Raquel acha que tem que haver a participação dos alunos, para não ficar aquela situação costumeira em que cada professor fica reclamando de sua classe, que os alunos são apáticos, que não participam, etc., etc.

Mesmo não sendo prevista a representação estudantil no conselho de escola da Célia Cintra, em virtude da pouca idade dos estudantes, como há representantes de classe para os conselhos de classe, estes são convidados a participar das reuniões como ouvintes. Mas Raquel, a diretora, se reporta a seu trabalho anterior em outras escolas para dizer que os alunos que participam dos conselhos de escola são os melhores, os mais disciplinados. Andreia, professora da terceira série, diz que os alunos gostam de participar no conselho.

Mesmo uma participação mais radical dos estudantes do ensino fundamental, que implicasse uma mudança na própria gestão escolar, aventada durante a entrevista, foi vista com certa simpatia pelos entrevistados. Assim, os educadores de modo geral não se opuseram a uma configuração institucional em que os estudantes tomassem parte efetiva da tomada de decisões, participando na elaboração de normas e procedimentos que dissessem respeito a sua vida escolar.

Marilda, professora da quarta série, se diz inteiramente favorável à participação das crianças nas decisões na escola. Diz que a Célia Cintra já está começando com isso, por meio dos representantes de classe. Ela se refere à participação dos alunos, levantando e solicitando soluções de questões, na escola, como

problema de banheiro, problema de corre-corre, machuca, quebra um dente, organização na fila para tomar merenda, por que que a quadra não está disponível para eles na hora do intervalo [...], por que que aqui nessa escola não existe uma cantina - por que têm muitos que não gostam da merenda...

Diz que está em vias de incrementar essa participação, organizando os alunos, não só de sua classe, mas de toda a escola.

Vanessa, professora da segunda série, afirma:

Eu acho assim: que se eles [os alunos] determinam as regras, eles se sentem mais na obrigação de cumprir do que uma regra que é imposta. 
Por exemplo, no começo do ano, a gente faz os combinados, as regras da sala. Então, eu deixo - lógico, eu vou orientando - mas eu deixo eles irem colocando esses combinados. Então é mais fácil também eu chegar e cobrar. Eu falo "Oh, vocês quiseram isso, agora vamos cumprir." Eu acho importante a participação dos alunos na decisão das regras, das normas. Eu acho até que eles deveriam participar mais. Eu acho também que os pequenos são mais coerentes até do que os maiores.

Mas, diante da perspectiva de se instalar uma escola com uma espécie de autogoverno, em que também os alunos influíssem na formulação das regras e controlassem seu cumprimento, Vanessa, embora concorde, mostra-se receosa.

Eu acho que aí tem de ter uma mudança muito, muito, muito grande. Porque a gente vem com essa ideia de sala de aula, de sentar... eu mesma, por mais que a gente saiba que hoje não tem que ser assim, que tem que mudar a prática, eu procuro mudar em pequenas coisas, mas eu... eu tenho medo também que caia na bagunça, que a coisa fique perdida... então a gente tem que estar muito, muito bem preparada para isso. E a própria sociedade, porque a cobrança dos pais é aquela coisa [tradicional].

Sobre os alunos fazerem as próprias regras, Márcia, vice-diretora, acha que é uma boa ideia. "Seria ótimo. Seriam os próprios alunos que fizessem as regras, orientados pelos adultos. Eu acho que aí eles iriam dar mais valor, sim." Pergunto: "E por que não se faz? Seria difícil fazer isso?" Resposta:

Eu acho que não, eu acho que não é difícil, se partir do trabalho da direção e professores, dos alunos em prol da escola; eu acho que seria aceito. Depende. Eu acho que pode até ser testado. Eu acho que daria certo. Porque quando eles participam, quando eles opinam, eles tendem mais a cumprir.

Elaine, professora da primeira série, sobre a participação dos alunos nas decisões: "Eu acho, assim, que sem aluno não tem escola e eu acho que eles deveriam, sim, mesmo os maiores, eu acho que deveriam participar, assim, das decisões da escola, que nem, aqui teve o conselho, eles são pequenos, mas alguns já deram opiniões boas." 
Andreia, professora da terceira série, diz que é favorável a regras e que elas devem ser obedecidas. Uma das regras na escola deveria ser que os alunos devem participar. Diz que, de primeira a quarta, por exemplo, na sala de aula, se estabelecem regras com os alunos, mas acabam esquecendo. É favorável a uma organização de escola em que houvesse regras feitas pelos alunos, de um modo diferente do que acontece na sala de aula.

\begin{abstract}
Mas aí, por exemplo, seriam alunos que estariam participando de um momento diferente da escola. Não é uma aula, é uma reunião, onde eles têm que participar, onde eles vão dar opinião, eles saberem o que está acontecendo, o que não está acontecendo, o que fazer. Talvez fosse para eles um momento de responsabilidade, em que eles estariam participando bastante da situação.
\end{abstract}

Sobre a participação do educando na gestão da escola, a coordenadora Vera Sanches é inteiramente favorável. "Porque a escola é dele. A escola é dele. Sabe por quê? Eu acredito que está faltando algum incentivo. Você ter prazer em falar 'Aquela escola é minha!' Sabe... 'Eu faço parte daquilo.'”

Em suma, o que se pode identificar no discurso de professores e demais trabalhadores escolares entrevistados é uma concepção em princípio favorável ao direito e à necessidade de autonomia do estudante. Mas tal visão não parece associar-se a uma conviç̧ão capaz de mover novas posturas e iniciativas na prática cotidiana. A estrutura e o funcionamento da escola continuam condizentes com uma prática pedagógica tradicional, e não se percebe nenhuma indignação significativa a respeito dessa situação, que continua à espera de políticas públicas que sejam orientadas por uma concepção de educação em que a autonomia do educando seja ao mesmo tempo um direito de quem se educa e um requisito para a realização efetiva dessa educação.

\title{
Síntese e conclusões
}

No contexto escolar, a promoção da autonomia do educando depende da própria realização da educação como prática democrática. Por um lado, no processo pedagógico, para que o educando queira aprender, é suposta a constituição de sua subjetividade (= condição de autor). Além disso, à medida que 
aprende, ele se apropria progressivamente de maiores porções de cultura, isto é, ele se faz mais autônomo, mais capaz de governar-se e fazer-se senhor de seu próprio caráter e personalidade.

Dessa perspectiva, o tema da autonomia se entrelaça com o da educação. Neste artigo, detivemo-nos em alguns temas sugeridos pela coleta de dados empíricos. Vimos, então, que um dos aspectos que os entrevistados associam à autonomia do educando é a disciplina. Para o exame dessa questão, recorremos à contribuição de Herbart (2003) a respeito da diferença entre governo e disciplina no contexto educacional. O primeiro tem caráter inflexível e deve ser respeitado irrestritamente, mesmo que o educando não consiga entender sua razão de ser. Já a disciplina faz parte da própria formação do indivíduo, de tal forma que, quando ela de fato se realiza, acaba por revelar-se como autodisciplina.

$\mathrm{Na}$ escola pesquisada, não foram relatados casos graves de indisciplina, o que foi reputado pelos depoentes à restrição do ensino, aí, ao primeiro ciclo do ensino fundamental, que recebe crianças muito novas e, por isso, com raros problemas de desobediência e rebeldia.

Com relação à ideia de uma participação mais radical dos estudantes na formulação de regras e tomadas de decisão na escola, os entrevistados se mostraram receptivos, embora alguns mostrassem certo receio de uma tão grande transformação no modo de ser da escola. A ideia, entretanto, parece decorrência natural da decisão de se levar às últimas consequências a necessária coerência entre a educação como prática democrática e o método utilizado para a gestão da agência em que se dá essa prática.

A realização da escola promotora de uma educação que consiga formar cidadãos autônomos, por meio de prática democrática, presente não apenas na situação de ensino, mas em todas as ações no âmbito escolar, é um empreendimento que exige o envolvimento de educadores providos de alta competência pedagógica, mas também de sólida formação política. Certamente a transformação da estrutura total da escola de modo a servir a esse propósito não é empresa fácil, mas é sempre preciso saber onde está o horizonte que impulsiona e orienta a ação dos homens. 


\section{REFERÊNCIAS}

BREMER, John; VON MOSCHZISKER, Michel. A revolução pedagógica: escola sem muros, o Programa Parkway de Filadélfia. São Paulo: Ibrasa, 1975.

CANÁRIO, Rui et al. (Org.). Escola da Ponte: um outro caminho para a educação. São Paulo: Didática Suplegraf, 2004.

CÂNDIDO, Antônio. A estrutura da escola. In: PEREIRA, Luiz; FORACCHI, Marialice M. Educação e sociedade: leituras de sociologia da educação. 6. ed. São Paulo: Nacional, 1974. p. 107-128.

ESCOLADE BARBIANA. Carta a uma professora: pelos rapazes da Escola de Barbiana. São Paulo: Centauro, [20-?].

FREINET, Célestin. A educação do trabalho. São Paulo: Martins Fontes, 1998. . Pedagogia do Bom Senso. São Paulo: Martins Fontes, 1996.

GRAMSCI, Antonio. Os intelectuais e a organização da cultura. 2. ed. Rio de Janeiro: Civilização Brasileira, 1978.

HERBART, Johann Friedrich. Pedagogia geral. Lisboa: Fundação Calouste Gulbenkian, 2003.

LINN, Susan. Crianças do consumo: a infầncia roubada. São Paulo: Instituto Alana, 2006. MAKARENKO, Anton. Poema pedagógico. São Paulo: 34, 2005.

NEIL, Alexander Sutherland. Liberdade sem medo: Summerhill: radical transformação na teoria e na prática da educação. 16. ed. São Paulo: Ibrasa, 1976.

PARO, Vitor Henrique. Estrutura da escola e educação como prática democrática. São Paulo: Feusp, 2010. 179 p. Relatório de Pesquisa.

PISTRAK. Fundamentos da escola do trabalho. São Paulo: Civilização Brasileira, 1981.

ROCHA, Gilmar. "Complexo de Emílio”. Da violência na escola à síndrome do medo contemporâneo. In: GONÇALVES, Luiz Alberto Oliveira; TOSTA, Sandra Pereira. (Org.). A síndrome do medo contemporâneo e a violência na escola. Belo Horizonte: Autêntica, 2008. p. 191-219.

Texto recebido em 02 de novembro de 2010 .

Texto aprovado em 18 de maio de 2011. 